\title{
Cultura-mundo hipermediada: os usos das redes sociais sob a lógica do hiperconsumo
}

\author{
Hypermediated world-culture: the uses of social \\ networks under byperconsumption logic
}

\begin{abstract}
Alexandre Honório da Silva
Doutorando do Programa de Pós-Graduação em Comunicação da Universidade Federal de Pernambuco (UFPE), Recife, PE Brasil, e-mail: alexandre.honorio@ufpe.br
\end{abstract}

\section{Resumo}

O artigo procura analisar os usos das redes sociais eletrônicas baseadas na internet adotando uma perspectiva na qual consumo e valores-usos da experiência nestas redes se colocam como evidências de um convívio hipermediado compartilhado. Propõe ainda perceber tais redes enquanto representações possíveis dos conceitos de cultura-mundo, proposto pelo filósofo francês Gilles Lipovetsky, e de hipermediação, proposto pelo pesquisador espanhol Carlos Scolari. Procura considerar que os fluxos e migrações que têm caracterizado contemporaneamente os usos destas redes refletem ainda a ascensão de interesses e socialidades compartilhadas. Para o artigo, os conceitos de hipermodernidade e hipermediação representam pistas para interpretações do sujeito das redes como afeito à reconfiguração constante dos vínculos que constrói em rede.

Palavras-chave: Hipermediações. Cultura-mundo. Hipermodernidade. Redes sociais.

\section{Abstract}

The article proposes an analysis of the uses of social networks based on Internet adopting an approach in which values consumption and uses of these networks experience represent an evidence of a bypermediated sharing. It also proposes to understand the social networks as representations to the concepts of culture-world, applied by the French philosopher Gilles Lipovetsky, and hypermediation proposed by the Spanish researcher Carlos Scolari. The article also consider the social network as the reflection of the migration flows that have characterized contemporary uses of these networks still, reflecting the rise of interest and socially shared. To the article, the concepts of byperconsumption and hypermediation represent some clues to interpretate the individual on the social networks as an user accustomed to constant reconfiguration of the ties that he rebuilds on the network.

Keywords: Hypermediation. Culture-world. Hypermodernity. Social networks. 


\section{Introdução}

Este artigo pretende analisar as redes sociais perpassadas por duas lógicas: uma proposta pelo pesquisador francês Gilles Lipovetsky e que aponta o sujeito da contemporaneidade como um hiperindivíduo, reflexo de uma cultura-mundo, permanentemente interligado, individualizado e ávido por uma "embriaguez dos contatos" e que parece ver nessa avidez uma definição possível de sua própria identidade (LIPOVETSKY; SERROY, 2010); e uma outra, proposta pelo pesquisador argentino Carlos Scolari, que compreende o sujeito dessa mesma contemporaneidade como reflexo da emergência da nova trama de reconfigurações, textualidades e hibridações que também o enredam (SCOLARI, 2008) em uma cadeia que recombina alta tecnologia e reconhecimento.

Assim, este trabalho pretende apontar essas redes como as instâncias contemporâneas de um convívio hipermediado; como pontos de partida portadores dos novos sabores do comunicar e capazes de evidenciar os novos humores do hipersujeito individual e hipermediado. Pretende ainda mostrar que esse hiperindivíduo (ou produsuário $^{1}$ ), por meio da interação compartilhada com o que consome/produz em rede, tem contribuído para reconfigurar os entornos simbólicos com que interage e tem se alçado como reflexo distintivo de uma hipermodernidade que reconhece suas demarcações, sua individualidade e sua ânsia por reconhecimento/pertencimento.

Para tanto, propõe que perceber que tal mudança implica não só compreender que as socialidades foram influenciadas pela ascensão das novas extensões da comunicação - e da redefinição resultante da estruturação de padrões de organização baseados na individualidade e na configuração de valores e afinidades próximas ao sujeito das redes
(CASTELLS, 2003) -, mas também reconhecer que, no âmbito da cultura informacional recente, estas possibilitaram um vislumbre possível de outra dimensão.

Este artigo sugere que os hiperconsumidores das redes também passaram a recombinar fruição da informação compartilhável e a experiência dos usos, reafirmando suas diferenças, seus modos de existir e manifestações de pertença e participação (CANCLINI, 2007) a partir do que é moldado por meio das suas interligações.

O hipermoderno e o hipermediado seriam, portanto, conceitos que refletiriam o estado dessa cultura construída com base em uma interpretação individual do saberes do social e do consumo a partir das redes. Assim, se a cultura-mundo exacerba as formas de sociabilidade ancoradas nos interesses individuais compartilhados entre seus agentes (CASTELLS, 2003), esta também impregna os sujeitos com suas demarcações, modelos e valores.

Como considera Lipovetsky, uma das facetas desse hiperconsumo - cujo reflexo é a ascensão de uma cultura-mundo ${ }^{2}$ - emerge do embaralhar cultural/informacional da realidade envolvida por um "tecnocapitalismo, das indústrias culturais, do consumismo total, das mídias e das redes digitais" (LIPOVETSKY; SERROY, 2010, p. 11). Assim, podemos perceber e considerar que, a partir da reconfiguração das dinâmicas cognitivas e culturais que as tecnologias digitais em rede puseram em prática contemporaneamente, o lugar do sujeito das redes tem sido o da reconfiguração dos vínculos, da adoção de novas formas de comunidade e do consumo em profusão como expressão de um processo coletivo (JENKINS, 2008) ancorado no reconhecimento das suas demarcações individuais.

Portanto, como propõe este artigo, pensar o cultural a partir de uma cultura-mundo é repensar o papel desempenhado pelos consumidores/produtores das

\footnotetext{
1 A ascensão do consumidor ao patamar de produtor de sentidos é um dos eixos do conceito de hipermediação proposto por Carlos Scolari, compreendendo o sujeito como parte dos processos de produção simbólica e, mais, sendo ele o responsável pela dissolução de uma distinção entre consumidor e produtor. As redes sociais eletrônicas baseadas na internet, portanto, contribuiriam para acentuar ainda mais esta perspectiva, com a assincronia do consumo que caracteriza os usos deste sujeito.

2 Para Lipovetsky, a cultura-mundo é a expressão do conceito de hipermodernidade, um período em que a excrescência de produtos, meios de comunicação e redes digitais transcende fronteiras e dissolve dicotomias. Essa cultura-mundo é, portanto, movida por um sentimento que eleva ao status de experiência a instantaneidade e a simultaneidade como expressões de um princípio individualizado da potência de si.
} 
redes de informação complexas construídas como consequência dos usos que têm feito desses dispositivos; é repensar o estado de coisas do consumo difratado que assedia o lugar múltiplo ocupado pelo indivíduo em face das demandas da cultura e do social; e, mais, é perceber o status que esse indivíduo ocupa perante as transformações da realidade simbólica que produz/compartilha individual e coletivamente.

\section{Esse sujeito hipermediado}

Assim, a grande questão aqui evidenciada diz respeito ao consumo - ou ao hiperconsumo - e como este termina por se enredar como artífice das transformações complexas desse sujeito social hipermediado recente (especialmente quando tratamos de uma manifestação relativamente recente como a ascensão das redes sociais) que ora interrogamos. Uma vez que, contemporaneamente, se afirmam por meio dos usos as novas formas expressivas que resultam da interdependência e interconexão crescentes e compartilhadas ${ }^{3}$, não chega a ser incoerente apontar que tais sujeitos alicerçam suas experiências nos humores do consumo.

Uma vez que vivenciamos "a época do mundo hipermediático, do cibermundo e da comunicação-mundo, estágio supremo, mercantilizado, da cultura" (LIPOVETSKY; SERROY, 2010, p. 14), é significativo observar que esse estágio representa não apenas a prevalência de uma esfera do exagero, da profusão, da onipresença da informação nos mais dispersos e complexos níveis, mas também o da ascensão dos modos de ativação da experiência individual.

Assim, perante a profusão informacional e a urgência por pertencimento que se faz perceptível contemporaneamente, temos um sujeito que reafirma sua individualidade ao mesmo tempo em que flerta com as demandas de um social cada vez mais vinculado eletronicamente. Portanto, quando nos confrontamos com a necessidade por onipresença e reconhecimento combinados à transitoriedade dos usos, chegamos, conforme pretendemos, ao sujeito das redes como conexão entre os dois horizontes referenciais aqui analisados.

O sujeito das redes se apresenta como espécie de agente de divergência/convergência hipermediada: as redes sociais representariam, portanto, janelas por meio das quais os sujeitos interrogariam uma cultura-mundo que é o território onde tal sujeito expressa/constrói/molda seus padrões individualizados de sociabilidade e reconhecimento (CASTELLS, 2003) - uma experiência individual/ coletiva em constante revolução e alçada ao status de consequência da hipermodernidade -, e lança mão do que reconhece como seu (identidade, individualidade, segmentação, pertencimento etc.).

Detentor de uma identidade desterritorializada, hipermediada e entremeada por atributos de autorreconhecimento e pertença resultantes de sua interação com os dispositivos e recursos que vê ao alcance das mãos, o sujeito das redes é revolvido pelos usos que faz da rede e pelo que a ela oferece em troca: valores, afinidades, proximidades que têm como norte comum a possibilidade que atribui a esse sujeito de erguer estruturas flexíveis de comunicação, interação e integração sociais calcadas tanto no reflexo de sua individualidade quanto na percepção de um quociente de pertencimento a partir dos laços que mobiliza (CASTELLS, 2003).

O sujeito hipermediado ${ }^{4}$, assim, flerta com os atributos de uma cultura-mundo que o investe, a um só tempo, com um misto complexo expressividade e hipertrofia dos usos. Ele ainda detém outros valores como pertencimento e implicação compartilhada integrados a sua percepção individualizada do

3 Dirá Lipovetsky que essa mesma cultura-mundo representa o desbunde do excesso: quando tudo se transforma em cultura e a própria cultura se torna um todo global (LIPOVETSKY; SERROY, 2010). Como afirma Lipovetsky, saem os símbolos distintivos das lutas (simbólicas) entre "grupos sociais detentores de pontos referenciais" e entra um mundo (simbólico) "cuja circunferência está em todo o lugar e seu centro em lugar nenhum".

4 O conceito de Hipermediação proposto por Carlos Scolari se harmoniza com o que observa Lipovetsky (2010): em uma miríade de usos possíveis, as tecnologias e as mídias eletrônicas possibilitariam aos sujeitos uma ressignificação do experimentado. Na descentralização dos usos residiria também o trunfo do sujeito perante a torrente informacional que o assedia: ele, o sujeito, é seu filtro; ele, o sujeito, tem o poder da escolha em suas mãos. 
contemporâneo - uma vez que elas, as redes, representariam o reflexo desse estágio contemporâneo do que emergiu com a disseminação da internet como terreno de migrações e experiência informacional em colaboração.

As redes sociais seriam, assim, o meio possível de representação desse novo mundo que é hipermoderno: um território convulsionante que assedia e engendra as representações de uma cultura-mundo hipermediada possível que recombina os novos signos de consumo, os novos e urgentes objetos de desejo e a sede constante por um estado de coisas hipertrofiado (LIPOVETSKY; SERROY, 2010) amalgamados em um composto complexo, desterritorializado e difratário que parece refletir os saberes em constante ebulição produzidos/propagados por sujeitos e suportes (KERCKHOVE, 1999); uma cultura construída por meio da coexistência e evolução entre usuários e tecnologias tramados em um processo constante de hipermediação (SCOLARI, 2008) cujo principal atributo é a prevalência da pertença como marco.

\section{Vivência hipertecnológica}

Dessa cultura-mundo hipermediada se apresenta, como podemos considerar a partir da lógica proposta por Lipovetsky, um indivíduo ao mesmo tempo liberto e imerso em uma cultura refratária calcada nos humores do tecnocomunicar; espécie de agente de uma hipercultura reflexo da convivência compartilhada submetida à lógica da técnica e dos espaços-virtuais ora convertidos em mercados da individualidade (VILCHES, 2003). Nesses mercados esse mesmo usuário é submetido à hipertrofia de sua individualização alicerçada na expansão das relações construídas sobre os alicerces da conectividade e dos múltiplos deslocamentos dos vínculos por ele estabelecidos.

Assim, o lançamento de um novo suporte comunicacional em rede - seja virtual ou físico-ativa e evidencia essa percepção: nenhuma aplicação em rede será suficientemente completa perante aquela revestida pelo signo da novidade e do novo lugar de envolvimento que promete; nenhum dispositivo será suficientemente útil em relação àquele sobre o qual pouco ou quase nada sabemos, mas que revestido pelo signo da novidade ganha a marca da urgência e da necessidade de implicação. Assim, a experiência de pertencimento hipermediada resulta involutariamente não apenas em espécie de estímulo à hiperindividualidade, mas também em igual dimensão na ativação da avidez pela manutenção do estatuto da emergência em relação ao que é novo.

Envolvido nas tramas das redes, das culturas e da experiência que emergem a partir das interligações que compartilha/tece, o sujeito hipermediado reconhece as ambiguidades de seu trânsito (ora individual, ora compartilhado) e está afeito às oposições que caracterizaram o lugar do sujeito do consumo ${ }^{5}$. Portanto, se é na manutenção da instantaneidade dos vínculos que reside seu horizonte de ação, ele reconhece a emergência dessa condição; se é no tour de force do culto ao imediato que subsistem seus atributos e seus outros modos de lidar tanto com o passado, o presente ou o que projeta na direção de seu futuro e suas expectativas quanto à experiência deste, ele percebe seu papel e condição de agente de interpelação.

O hiperindivíduo das redes sociais eletrônicas é a representação de um sujeito imerso em sua individualidade, mas em suspensão quanto às pressões simbólicas que o envolvem; um indivíduo que reconhece na onipresença e a instantaneidade dos suportes com os quais interage a chave para a manutenção de seus vínculos e o roteiro para seus movimentos entre experiências. O modelo de relação que interconecta esse sujeito deriva do que as redes promovem não apenas quanto à interação que o relaciona em um contexto de colaboração/ comunidade, mas também pelos vínculos individuais que estabelece entre os demais usuários revolvendo a cadeia de contatos compartilhados e reconfigurando seus atributos de individualização.

\footnotetext{
5 Opto por adotar a mesma referência de Lipovetsky aos chamados três momentos distintivos da cultura: um primeiro, que identifica a cultura em suas manifestações mais primitivas (ligadas aos elementos religiosos-tradicionais da cultura); um segundo momento, que relaciona a cultura com a ascensão das democracias modernas e a oposição entre cultura e os valores do dinheiro e do comércio; e um terceiro momento, com o declínio das grandes utopias e a ascensão de uma cultura-mundo hipermodernizada e ora regidas pelas lógicas do consumo e do individualismo tecnoaditivados.
} 
As redes impregnam os tais vínculos dessa mesma cadeia com os componentes almejados por esse hiperindivíduo quanto à sua emergência/urgência por reconhecimento e vinculação - por isso é relativamente comum a percepção de que tais redes parecem intercalar os usuários que potencialmente compartilham dos mesmos interesses, que se assemelham pelas experiências e que se interligam pelas preferências em comum.

O sujeito hipermediado das redes sociais é, desse modo, reflexo de um excedente informacional que interpela essa cultura profusa que interroga sua individualidade e os usos de seus atributos em compartilhamento: ele segue a bússola do que experimenta/compartilha/produz e tudo o que faz tem como meta uma procura ininterrupta por algum novo signo de distinção/implicação/vinculação (VILCHES, 2003).

Ele, orientado pela ação e pela contemplação (ENZENSBERGER, 2003) de sua individualidade e do que dela emerge, não cobra uma desintegração caótica e recorrente de sua rede de vínculos e a liquidação de seus atributos individuais (BAUMAN, 2005), mas, sim, a aparente percepção de sua nova condição quanto à aparente reconfiguração que promove em seus percursos migratórios dos vínculos que compartilha.

Um aspecto que podemos perceber desse sujeito hipermediado diz respeito à natureza polissêmica que cultiva perante as transformações que o cercam nos planos da cultura e do social plasmado pelas redes: seguir a multidão quando não existem referências é uma marca daqueles que, mesmo lançando mão da capacidade individual de conduzir a si, "manifestam dependência e impotência subjetivas" (LIPOVETSKY; SERROY, 2010, p. 73) quanto às demarcações contemporâneas da implicação. Mais que isso, o sujeito hipermediado é uma representação dos dispositivos e das modalidades de interação que emprega em sua busca por implicação, já que a existência desse sujeito dentro do universo interativo dos usos depende da percepção dos demais sujeitos também como interfaces (SCOLARI, 2004).

Há, portanto, outra lógica possível para perceber o que rege o passeio do sujeito hipermediado das redes: essa é a lógica da efemeridade do real, desse apego ao transitório e à renovação permanente da experiência de uma interface recombinada e compartilhada inerente ao sujeito dessa cultura-mundo. O sujeito hipermediado é parte da memória disponível a partir do social: um suporte de leitura e escrita cujo acesso se dá a partir dos usos que faz de seus atributos de individualidade e socialidade (ENZENSBERGER, 2003).

É nessa percepção que se alicerça seu trânsito individualizado, repleto dos excedentes consumíveis, prováveis, tocáveis e dignos de experimentação e, por consequência, da implicação de sua igualmente complexa necessidade por comunidade. $\mathrm{E}$ no efêmero que esse sujeito reconhece o lugar no qual se encontra e o papel que deve desempenhar.

A lógica que rege as indústrias culturais é uma lógica de diversificação permanente, uma lógica de novidade e obsolescência aceleradas. O temporário é a lei, tanto estética como econômica, da cultura de massas, acompanhando estruturalmente o mundo moderno da velocidade e da inovação permanentes (LIPOVETSKY; SERROY, 2010, p. 89).

O sujeito que ascende a partir da disseminação dos microcomputadores, do surgimento dos modernos meios de comunicação de massas, do desenvolvimento dos conceitos de multimídia e da consolidação da internet como zona de convívio impôs compartilhamento de uma linguagem/ experiência comum que o alçou a outro status: ele é um sujeito hipermediado que surfa nas ondas de uma rede regida pelo signo do hiperconsumo e da hiperpresença.

É, ainda, como resultado dessa ascensão um sujeito afeito às veleidades e às verdades que o assediam em vagas informacionais, culturais, econômicas e sociais, já que as esferas econômica, social e cultural que enredam real encontram-se em remodelação a cargo não só desse sujeito hipermediado e dos seus movimentos, mas também da própria configuração de uma sociedade de hiperconsumidores que, alicerçados pela multiplicidade de possibilidade e suportes, intervêm no próprio tecido da experiência compartilhada.

O individualismo hipermoderno não é só consumista, mas é também expressivo, comunicacional, participante, à procura de interações múltiplas. Embora o consumo funcione muitas 
vezes como um consolo para as misérias da vida, o novo tropismo comunicacional revela, por seu lado, as insatisfações da vida 'passiva', absorvida no consumismo (LIPOVETSKY; SERROY, 2010, p. 98).

Entrecortar, revolver e intervir são verbos caros ao sujeito hipermediado. Mas como defini-lo? Ele é reflexo do status recente dos indivíduos envolvidos pela cadeia de elementos de uma existência regida pela hipermodernidade. Ele, o sujeito hipermediado, é a tradução de um modelo no qual consumo, experiência e multiplicidade caminham de mãos dadas: é dessa combinação que ele insurge na direção do status quo que procura percebê-lo como parte de um conjunto homogêneo.

O sujeito hipermediado é a menor representação de uma cultura-mundo que éo "indivíduo obrigado a criar a si mesmo sem redes que o protejam quando da queda" (LIPOVETSKY; SERROY, 2010, p. 176) que a existência propõe. Ele, o sujeito hipermediado, não é refém dos prazeres do consumo, mas, mais ainda, é cúmplice do hiperconsumo que o engendra, pois é das entranhas dele que esse mesmo indivíduo retira seus elementos identitários mais caros.

É em torno de tal contexto que as redes sociais eletrônicas se inserem. Tendo como eixo de sustentação primordial do individualismo em exacerbação do sujeito hipermediado, as redes sociais ilustram aspectos relevantes sobre a relação entre hipermodernidade e hipermediação cultural - elementos caros à compreensão do que se dá contemporâneamente quanto às socialidades e, mais que isso, à experiência compartilhada cotidianamente.

\section{Redes hipermediadas}

As redes sociais são a melhor representação do conceito de hipermodernidade. Em torno delas e dos seus usuários são perceptíveis os conflitos, os humores e os elementos básicos de uma cultura-mundo em torno da qual padrões que envolvem o culto ao individualismo, a representação hiperdimensionada do Eu, a onipresença da informação, a urgência dos usos e a transitoriedade do que se experimenta são demarcações inelutáveis e complexas.

Acrescente a tais elementos a interação com suportes relacionados à esfera de comunidade que compartilham e o fato de esses mesmos sujeitos-mundo cultivam como marca a heterogeneidade de seus movimentos: pronto, chegamos à dimensão do que se dá nas redes sociais eletrônicas contemporâneas e aquilo que esses sujeitos esperam dela obter.

Sabemos que o individualismo em rede, mais que apenas um reflexo isolado, é um padrão social. Os sujeitos montam suas redes basicamente visando a experimentar. É preciso distinguir a experimentação do consumo: na experimentação há a expectativa dos usos; o consumo encerra satisfação com o que se consome.

A natureza do indivíduo em rede é experimentar e compartilhar a satisfação obtida: o que importa, mais que o consumo, é o relato difundido em relação ao que se experimenta. Por isso, as redes contribuem para formar comunidades encerradas nos mais diferentes níveis de ligação, já que ligar e desligar define, sobretudo, as instâncias dessa experimentação coletivas e participativas.

Mas essas redes de sujeitos que procuram compartilhar informações em diversos níveis de interligação revelam, sobretudo, que a própria cultura em torno das redes sociais ou da própria internet é, sobremaneira, alicerçada na "crença tecnocrática do progresso dos indivíduos através da tecnologia, levada a cabo por comunidades" (CASTELLS, 2003, p. 53) que navegam no imediatismo inerente à criatividade tecnológica contemporânea compartilhada.

É necessário, por sua vez, perceber as redes sociais como manifestações de uma representação do social contemporâneo mediados pelos usos que os sujeitos desse mesmo social promovem dos suportes e do excedente comunicacional/informacional. De um lado há, em relação a essas redes, a representação de uma hipermodernidade revolvida pelos estatutos do consumo; de outro, individualidade, onipresença e interatividade que brotam como resultado desse ininterrupto experimentar hipermediado.

Se o sujeito hipermediado é espécie de eixo em revolução que se faz imperceptível em seu trânsito por meio das redes que articula, ele se faz reconhecível/perceptível como resultado da contaminação/ interferência/participação nos compostos de uma cultura-mundo que pertença a uma teia/cadeia de saberes e experiências que emerge da participação reativa.

Esse mesmo sujeito hipermoderno, mais que consumir, reconfigura os usos das redes tendo por horizonte maior a ampliação da participação 
inerentes a tais usos: ele, diante do que promovem as redes sociais eletrônicas, se apresenta como elemento de hibridação, de contaminação, enfim: participa dos processos de produção inerentes à cultura que emerge das redes e de sua natureza hipermediada.

O consumo se insurge, portanto, mais que um modo de ser contido em uma cadeia sucessiva de trocas, em participação: o indivíduo hipermoderno tem no consumo um elemento de representação até mesmo de demarcação - do que experimenta ou procura imprimir por intermédio de seu consumo. Diante disso, por exemplo, quando o sujeito hipermediado migra de uma a outra rede, mais que a busca por satisfação por meio do consumo, procura, mais, implicação e participação; procura sobremaneira por instâncias nas quais sua participação signifique algo.

\section{Migração hipermediada}

Essa migração volatilizada é dependente de uma expressão de urgência ou necessidade inerente a quase tudo na hipermodernidade. Um produto nunca é completo; nunca é definitivo: todo produto detém validade e, como consequência, têm seus graus de relevânciaimpressos subcutaneamente no tecidohipermediadoculturalmente-especialmente quando direcionamos nosso olhar na direção das redes sociais. Nelas, não só a urgência, mas elementos culturais, sociais e econômicos entram em constantes entrechoques.

Esses elementos determinam não só os usos, mas, mais que isso, a abrangência, a extensão, a relevância ou a validade dessas redes, já que inovação, criação, risco, aventura e originalidade são eminentemente valorizados como motores das paixões que movem as multidões por meio dessas redes envolvidas por motivações e contradições as mais diversas, atribuindo a uma tribo complexa de hipermodernos sentidos que identifica seus indivíduos a partir de suas posturas de expressão e insatisfação constantes (LIPOVETSKY; SERROY, 2010).

As redes sociais eletrônicas baseadas na internet representam modelos desse tipo de expressão do sujeito envolvido pelo hipermoderno contemporâneo, já que nelas se desenvolvem as transformações envolvendo, como exemplo, a simultaneidade das experiências que caracterizavam os usos coletivos das mídias eletrônicas anteriores à ascensão da internet (Gráfico 1).

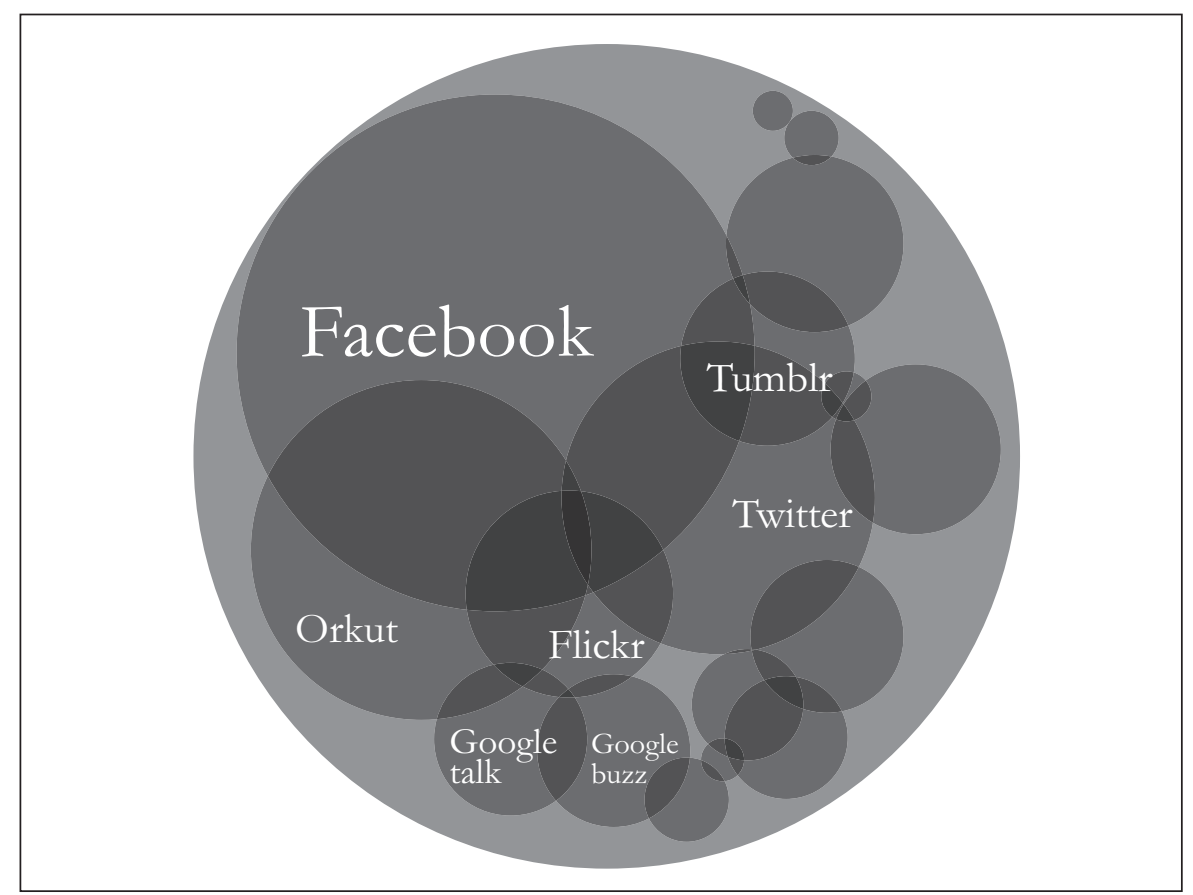

Gráfico 1 - Modelo de deslocamentos/interações entre usuários e redes sociais tendo como padrão os movimentos de migração e representação. Fonte: Dados da pesquisa. 
SILVA, A. H. da.

Com a hipermodernidade, entramos em um mundo global onde todos podem consumir os mesmos produtos culturais, bem como interrogar os processos que resultam nesses mesmos produtos. Com a ascensão das redes sociais e de seus usuários, estes últimos passaram à linha de frente tanto do que se refere ao consumo (ou hiperconsumo, se preferir) quanto à produção de informação e significados.

Recorrendo a Scolari (2008), as redes sociais são a manifestação mais clara dos processos de troca que caracterizariam essa tal trama de significações, trocas, produção e linguagens que emprestam seus contornos e seus fenômenos a essa tal hipermodernidade e, mais, ao sujeito hipermediado que dela parece resultar. Como define o pesquisador, o espaço hipermediado onde esse sujeito parece transitar, o mesmo espaço compartilhado por outros iguais - um espaço no qual as redes sociais eletrônicas desempenham um significativo intercâmbio informativo/ tecnológico/comunicacional-, é tal qual um "buraco negro que atrai, absorve e integra” (SCOLARI, 2008, p. 277) tudo o que se aproxima ou relaciona com seu campo de atração.

São esses metaprodutos que estimulam os humores desses sujeitos-mundo: usos que resultam da hipertextualidade, interatividade e recombinação de saberes culminando em um grande mercado ao ar livre, caótico, em constante mutação o qual cobra dos seus hiperconsumidores espécie de sintonia com tal caos. Por meio da internet, e mais notadamente por meio das redes sociais que nela têm seu suporte primordial, sujeitos exercitam a construção de um mundo em efervescência cultural-simbólica regido, sobretudo, por uma combinação entre consumo, experiências colaborativas e hibridações.

\section{Referências}

BAUMAN, Z. Vida líquida. Rio de Janeiro: Jorge Zahar, 2005.

CANCLINI, N. G. Diferentes, desiguais e desconectados. Rio de Janeiro: Ed. da UFRJ, 2007.

CASTELLS, M. A galáxia da internet. Rio de Janeiro: Jorge Zahar, 2003.

ENZENSBERGER, H. M. Elementos para uma teoria dos meios de comunicação. São Paulo: Conrad, 2003.
JENKINS, H. Cultura da convergência. São Paulo: Aleph, 2008.

KERCKHOVE, D. de. Inteligencias en conexión: hacia una sociedad de la web. Barcelona: Gedisa, 1999.

LIPOVETSKY, G.; SERROY, J. A cultura mundo: resposta a uma sociedade desorientada. Lisboa: Edições 70, 2010.

SCOLARI, C. Hacer Clic: hacia una sociosemiótica de las interacciones digitales. Barcelona: Gedisa, 2004.

SCOLARI, C. Hipermediaciones: elementos para una Teoría de la Comunicación Digital Interactiva. Barcelona: Gedisa, 2008.

VILCHES, L. A migração digital. São Paulo: Loyola, 2003.

Recebido: 17/02/2011

Received: 02/17/2011

Aprovado: 24/03/2011

Approved: 03/24/2011 